\title{
Product perishability and multistore grocery shopping
}

\author{
Robert E. Krider ${ }^{\mathrm{a}, *}$, Charles B. Weinberg ${ }^{\mathrm{b}}$ \\ ${ }^{a}$ School of Business and Management, Hong Kong University of Science and Technology, Clear Water Bay Road, Kowloon, Hong Kong \\ ${ }^{\mathrm{b}}$ Faculty of Commerce and Business Administration, University of British Columbia, Vancouver, BC, Canada V6T 1 Y 8
}

\begin{abstract}
Perishability, a largely unconsidered characteristic of consumer goods, is shown to play an important role in planned multistore shopping behavior. We present a model of consumers as cost minimizing inventory managers, who choose between two stores differentiated on location and price, and who purchase perishable and nonperishable goods. We show that the interaction between perishability of goods and price differences of stores can be an important driving force for planned multistore shopping. This rationale leads to a set of propositions. One unexpected result is that as the known price difference on a basket of identical goods increases between two stores, shoppers making store choice decisions on the basis of the basket price are more likely to shop regularly at both stores. We present survey results supporting our model's predictions. (C) 1999 Elsevier Science Ltd. All rights reserved.
\end{abstract}

Keywords: Store choice; Purchase timing; Perishability

\section{Introduction}

The majority of consumers shop regularly at more than one retail grocery outlet (Arnold et al., 1983; Hortman et al., 1990; Kahn and Schmittlein, 1992; Uncles and Ehrenberg, 1990; Urbany et al., 1996), yet our understanding of why this important behavior occurs remains limited. Store-switching in response to promotions, as is shown in studies of cross-store price elasticities (Kumar and Leone, 1988; Walters, 1991), as well as observational studies (Mulhern and Padgett, 1995) can have an effect, but its magnitude is too small to explain the majority of multistore shopping (Urbany et al., 1996). While the prevalence of one-stop shopping due to broad supermarket assortment has increased dramatically over the last few decades (Messinger and Narasimhan, 1997), the "one-stop" continues to be made at more than one supermarket.

Complicating the issue is the fact that, while consumers may not have accurate price knowledge of individual brands even immediately after purchase (Dickson and Sawyer, 1990), they do have good knowledge of the

\footnotetext{
* Corresponding author. Tel.: (852) 2358-7701; fax: (852) 2358-2429;

E-mail address: mkkrider@usthk.ust.hk (R.E. Krider)
}

relative price levels across stores (Urbany et al., 1996). Similarly, consumers consistently identify price as a major factor in grocery store choice studies, and have little difficulty in identifying stores with overall low prices (Arnold, et al., 1983; Hortman et al., 1990; Louviere et al., 1996). Widespread consumer knowledge of overall relative prices and the importance of overall price in store choice, coupled with limited across-store shopping for specials, suggests that many consumers plan their shopping trips to stores on the basis of their expectations of the long-run relative price of a shopping basket of goods, rather than on the basis of current promotions. Why would a knowledgeable consumer, who makes storechoice decisions on the basis of the long-run price of a basket of goods, engage in regular and frequent multistore shopping, ${ }^{1}$ rather than simply patronizing the store that provides the best average prices for the desired basket of goods?

One possibility is suggested by the multipurpose shopping literature (e.g., Ingene and Ghosh, 1990), where

\footnotetext{
${ }^{1}$ A trivial possibility is that, even in the long run, different stores provide better deals on different products, and consumers learn these differences-they "cherry-pick" on the long-term differences. Aside from triviality, this has obvious problems with face validity, and we are careful to preclude this possibility in our modeling.
} 
spatial shopping models produce planned normative one-stop shopping to different locations on different trips. $^{2}$ The different centers in their model, however, do not sell identical assortments. Different assortments may be sufficient to drive some multistore grocery shopping, but the assortments offered by competing grocery stores largely overlap. Is one-stop multistore shopping ever optimal when competing stores carry identical goods?

In this research, we provide a normative rationale for one-stop multistore shopping that helps answer the preceding questions, and that is, we believe, intuitively appealing. Our analysis, like Messinger and Narasimhan (1997) and Ingene and Ghosh (1990), deliberately abstracts from short-term effects such as cherry-picking and forward buying, to concentrate on long-term decisions. It hinges on the structure of consumers' inventory costs differing between perishables and nonperishables. Household disincentives for purchasing large quantities of nonperishables arise mainly from transport and storage space limitations. Stockpiling costs are thus increasing in quantity purchased per trip, and can be traded off against time-average trip costs, which are decreasing in quantity purchased per trip. Perishables, on the other hand, will suffer spoilage and any amount that cannot be consumed before spoilage must be disposed of. Avoiding such loss is the main constraint on stockpiling of perishables, and this cost cannot be traded off against trip costs. It is surprising that the role of perishable goods in consumer store choice has received very little attention from marketing academics, considering the importance of perishables to grocery retailers. For example, of the 389 billion dollar US grocery market, $47 \%$ is spent on perishables, and $29 \%$ on dry groceries, with the balance on nonfood items (Supermarket Business' September 1996 Consumer Expenditure Survey).

Our approach is to develop first an analytic model of store choice for cost-minimizing consumers. Given a discount store and a regular store selling identical perishable and nonperishable products, differentiated only on location and price, we find analytic expressions for optimal store choice, trip frequency, and quantities purchased, for three patterns: shopping at only the discount store, only the regular store, or both. We follow this with across-pattern numeric analyses to study which optimal pattern will give the lowest cost as exogenous factors (price differentials and storage costs) vary. The focus is to identify the factors that favor two-store shopping, and to analyze the model implications for market share response to price and consumer stockpiling costs.

\footnotetext{
${ }^{2}$ The one-stop is at a shopping center, where high and/or low order goods may be purchased, and hence may be multipurpose. Different trips may be to different centers, which is analagous to our notion of long-term planned multistore, but one-stop-per-trip, shopping. This is in contrast to "cherry-picking" models, such as Lal and Rao's (1997) single-period model.
}

We also use the theory to generate new predictions with which to challenge the model. One unexpected result is increasing returns to scale in price differences between the stores: at small price differences, the market share of the discount store is roughly linear with price advantage; however as the price advantage increases, the discount store's share increases more than proportionally over a broad range, until it is near $100 \%$. Another interesting consequence of considering perishability is that the shorter the lifetime of the perishable good, the less impact a discount store has on a regular price store. Marketing programs which attempt to increase consumer sensitivity to freshness, and hence decrease effective lifetimes of perishable foods, may therefore help the regular store. Conversely, while increasing the shelf life (by means such as producing new hybrid varieties of produce) helps both stores while the good is in the store, it hurts the regular store more once the good is on the consumer's shelf.

A recent Wall Street Journal article discussing supermarket response to the success of the discount supercenters, states that "playing off a perceived weakness of supercenters, [supermarket chains] are also promoting the quality and freshness of their perishables" (Coleman, 1997). Our research helps to understand the demand-side factors contributing to the discounters' weakness. The model implies that, all else equal, discounters will capture a larger market share in nonperishables than in perishables. This natural relative strength in nonperishables could easily lead to further neglect of perishables.

Data to substantiate market share effects, such as increasing returns and share differences between perishables and nonperishables, are difficult to find. We provide anecdotal evidence consistent with increasing returns, however. Building on model results, we also generate propositions about grocery shopping behavior at the consumer level. We conduct a field survey to test these propositions and find strong support for our analysis.

This work draws on research in three areas: multipurpose shopping, consumer stockpiling in response to promotions, and inventory control theory.

Multipurpose shopping: Multipurpose shopping refers to the observation that consumers will make a single trip to a central location to purchase more than one good or service, resulting in retail agglomeration. The cost minimization framework has been used to show explicitly how qualitatively different kinds of retail centers might arise (e.g., Bacon, 1984). The model developed in this research is similar in spirit to the multipurpose shopping literature in that consumers are assumed to make a choice on the basis of cost minimization over transportation, inventory, and price costs. We build on previous work (e.g., Ghosh and McLafferty, 1984; Ingene and Ghosh, 1990; McLafferty and Ghosh, 1986) by modeling the case where two goods are offered in different locations. We depart from this work, however, by allowing 
each outlet to offer both goods, rather than each outlet offering only one good, and by allowing the outlets at different locations to charge different prices. This is because our focus is on shopping behaviors when stores are differentiated by price and location, rather than on agglomeration issues that are the focus of the multipurpose shopping models. The difference in focus becomes apparent when comparing our work to Bacon (1984), who also analyzes shopping behavior when quantities, trip frequencies, and purchase location are endogenous. While he allows price differences between centers, he only solves the two-good, two-center problem for a constant value constraint, which renders the total cost independent of prices, and sets market boundaries equidistant from different-price stores; and he solves the quantity constrained problem (where price differentials matter) only for the one-good, two-center case. This is sufficient for his purposes of addressing how different purchase frequencies can arise for different goods, which in turn can lead to hierarchical agglomeration, or central places. We study the more complex combined problem of constant consumption rates (a quantity constraint) in the two-good, two-center case, because we do not expect total costs or shopping boundaries to be independent of price, and because we are interested in the situation where stores sell an identical assortment of goods.

Most importantly, we also differentiate the two goods by their inventory cost structure, to reflect the differences in how perishables and nonperishables must be handled by consumers. Multipurpose shopping models, in contrast, usually use a simple and tractable interest expense component (or, in the case of Lentnek et al., a depreciation loss) to model inventory costs.

Promotion and stockpiling: Previous work on the relation between consumer stockpiling and promotions establishes the value of normative inventory control models in consumer shopping (for a review of the promotions literature, see Blattberg and Neslin, 1993). Recent examples are Meyer and Assuncao (1990) and Krishna (1994) who derive implications for promotions assuming consumers behave as inventory managers, and who also provide empirical evidence that this is a reasonable model of shopping behavior.

Inventory Control: The situation modelled falls into the class of joint replenishment problems (JRP), which "is among the most studied of inventory problems" (Atkins, 1993) (see Muckstadt and Roundy (1993) for a survey of this literature). Joint replenishment refers to the problem of maintaining inventory of more than one good, when there is the possibility of reducing replenishment costs by ordering the goods simultaneously. Here, the joint cost is the transportation cost.

The form of the perishability costs, as described below, is taken from the literature on perishable goods replenishment policies (see Nahmias, 1982, for a review).

\section{Model development}

Supply characteristics - goods, stores, and prices: Two goods, one perishable and one nonperishable, denoted by subscripts ${ }_{p}$ and ${ }_{n}$, are available to consumers. Each of the two goods is available at two stores, differentiated by price and location. For expositional clarity we label the stores discount and regular, with subscripts ${ }_{\mathrm{d}}$ and ${ }_{\mathrm{r}}$. Thus, there are four prices: $P_{n, d}, P_{n, r}, P_{p, d}$, and $P_{p, r}$.

Demand: Each of the two goods are consumed at the constant rates $D_{\mathrm{n}}$ and $D_{\mathrm{p}}$. Also, since the consumer never goes hungry, no consumer stockouts are allowed.

Consumer cost structure: Consumers minimize longrun average costs over an infinite horizon. Total costs consist of trip costs $C_{\mathrm{t}}$, plus inventory costs $C_{\mathrm{s}}$, plus the price of the goods $C_{\mathrm{p}}$.

Trip costs, for each consumer, consist of a fixed amount $c_{\mathrm{r}}$ or $c_{\mathrm{d}}$ incurred for each trip to the regular or discount store.

Inventory cost structures differ for the perishable and the nonperishable good. Consumers have quantity-dependent instantaneous storage costs $s \cdot Q_{\mathrm{n}}(t)$ for the nonperishable good, where $s$ is the cost per unit quantity per unit time, and $Q_{\mathrm{n}}(t)$ is the quantity of the nonperishable good on hand at time $t$. This formulation is consistent with recent conceptualizations of consumer disincentives to purchase large quantities of nonperishables, such as Krishna (1994), where quantity-dependent holding costs for consumers are used. It is also empirically supported by Raju (1992), who showed that, while the relationship between (nonperishable) category expensiveness and sales variability was not statistically significant, bulky categories had significantly lower variability. ${ }^{3}$ Thus, stockpiling disincentives are more due to quantity than price - intuitively, consumers care mainly about the space taken up by the goods. The parameter, $s$, will of course depend on previous investments in capacity, but the capacity decision is a one-time decision prior to, and therefore beyond the scope of, our problem.

An amount $Q_{\mathrm{n}}$ of the nonperishable purchased and immediately consumed at the constant rate $D_{\mathrm{n}}$ will have a storage cost:

$$
\begin{gathered}
\int_{t_{0}}^{t_{0}+Q_{\mathrm{n}} / D_{\mathrm{n}}} s\left(Q_{\mathrm{n}}-D_{\mathrm{n}} t\right) \mathrm{d} t=\frac{s Q_{\mathrm{n}}^{2}}{2 D_{\mathrm{n}}} \\
=\frac{s Q_{\mathrm{n}} \Delta t}{2}=\frac{s D_{\mathrm{n}}(\Delta t)^{2}}{2}
\end{gathered}
$$

Following the OR literature on inventory management of perishables (e.g., Nahmias, 1982), the perishable

\footnotetext{
${ }^{3}$ The assumption is that sales variability is at least partially reflecting stockpiling in response to price changes. If consumer stockpiling costs are related to the money invested in the goods, variability should be related to expensiveness. If the costs are related to quantity purchased due to storage limitations, variability should be related to bulkiness.
} 
good has a lifetime $\Delta t_{\mathrm{e}}$ after purchase, and incurs an inventory cost equal to the price paid for any quantities that expire before they are consumed, and must be disposed of. Because our interest is in the consequences to shopping patterns of the unique characteristics of perishables, we ignore their quantity-dependent storage costs. It can easily be shown that when a single good has both types of costs, either one or the other will control shopping frequency. In other words, the consumer will replenish a perishable good at periods equal to the lifetime of the good unless quantity-dependent storage costs are sufficiently high to shorten the shopping period. Abstracting from quantity-dependent costs implies that perishability costs always dominate. In the case where storage costs control the perishable purchases, the problem becomes a simpler one of two nonperishables.

Consistent with much of the literature, the time value of money is assumed negligible compared to other costs.

\subsection{Decision variables and solution method}

The consumer decides when to shop at which store, and how much to buy of each good. We formalize the decision by identifying shopping patterns, or sequences of visits to the stores (for example the sequence "(1) discount, (2) regular, (3) regular, (4) regular, (5) discount") and associated sequences of types of good purchased (for example, "(1) perishable and nonperishable, (2) perishable, (3) perishable, (4) perishable, (5) perishable and nonperishable"). For the $i$ th visit to the discount store and the $j$ th visit to the regular store, we optimize over purchase quantities $Q_{\mathrm{n}, \mathrm{d}, i}, Q_{\mathrm{n}, \mathrm{r}, j}, Q_{\mathrm{p}, \mathrm{d}, i}, Q_{\mathrm{p}, \mathrm{r}, j}$ and trip timing $t_{\mathrm{d}, i}$ and $t_{\mathrm{r}, j}$. The infinity of possible shopping patterns, each with its own unique cost structure, poses a major problem in optimization. Krider (1993) shows that only 6 possible optimal patterns exist. ${ }^{4}$ Shopping exclusively at one store or the other accounts for two patterns. A third involves shopping for both perishables and nonperishables at the discount store at regular intervals, with fill-in trips for the perishable alone at the regular store. For example, the customer might make a monthly trip to a distant discount store to purchase one month's supply of spaghetti and one week's supply of tomatoes, and then make weekly fill-in trips to a nearby regular supermarket to restock tomatoes. The final three theoretically possible patterns are two-store patterns, but all involve making fill-in trips for the nonperishable only, at the regular store. In the interest of tractability and interpretability, we abstract from these final three patterns, noting that this may slightly understate the extent of multistore shopping. We also note that it seems unlikely that a significant number

\footnotetext{
${ }^{4}$ Each of the six are periodic, and each admits an interior and boundary solution depending on whether or not the perishability constraint binds, for a total of twelve structurally different optimal cost functions.
}

of consumers would use such two-store patterns as part of planned long-term shopping strategies in any realistic shopping environment.

The three patterns of interest determine six (perishability constraint binding and nonbinding for each pattern) cost functions, which are minimized over the decision variables. For any set of parameter values, the smallest of the six minimal cost functions determines the optimal pattern, the pattern used by the customer facing those parameters. To determine when a customer changes shopping pattern with a change in any model parameter, it is then necessary to find the parameter value that gives the 5 possible intersections between this cost function and the other five minimal cost functions, and determining which of these intersections occurs at the lowest cost.

Notation is summarized in Table 1. All parameters are positive real. Quantities are non-negative real.

\section{Optimal policies}

\subsection{Shopping at one store only}

If the parameters are such that consumers only frequent one store, the solution to the problem is straightforward. A controlling constraint is the "perishability constraint",

$$
\Delta t_{i} \leq \Delta t_{e}
$$

which states that the purchase interval cannot exceed the lifetime of the perishable good. It can easily be shown that a trip will only be made when both goods'

Table 1

Notation

Subscripts:
$n$ : non-perishable
p: perishable
r: regular (expensive) store
d: discount store
$i$ : visit index to discount store
$j$ : visit index to regular store

$Q_{\mathrm{n}, \mathrm{d}}, Q_{\mathrm{n}, \mathrm{r}}, Q_{\mathrm{p}, \mathrm{d}}, Q_{\mathrm{p}, \mathrm{r}} \quad:$ quantities of each good purchased at each store (time subscript omitted)

$P_{\mathrm{n}, \mathrm{d}}, P_{\mathrm{n}, \mathrm{r}}, P_{\mathrm{p}, \mathrm{d}}, P_{\mathrm{p}, \mathrm{r}} \quad:$ prices of each good at each store

$t_{\mathrm{d}, \mathrm{i}}, t_{\mathrm{r}, j} \quad:$ time of $i$ th $(j$ th) visit to each store

$\Delta t_{\mathrm{d}, \mathrm{i}}, \Delta t_{\mathrm{r}, j} \quad:$ time intervals between purchases

$D_{\mathrm{n}}, D_{\mathrm{p}} \quad$ : consumption rate of each good

$\Delta t_{\mathrm{e}} \quad$ : time between purchase and expiry of perishable good

$s \quad$ : instantaneous storage cost of non-perishable good

$c_{\mathrm{d}}, c_{\mathrm{r}} \quad:$ trip cost to each store

$C_{\mathrm{t}} \quad:$ long-run average trip costs

$C_{\mathrm{s}} \quad:$ long-run average storage costs

$C_{\mathrm{p}} \quad:$ long-run average price costs

C : total long-run average costs 
inventories have just reached zero ("zero inventory condition"), and that both goods will be purchased on each trip. Therefore, there is only one shopping pattern, with one associated cost function to be minimized. As the basic solution is the same for both the discount and regular stores, we temporarily drop the store subscripts. The optimal quantities and purchase intervals are

$$
\begin{aligned}
& Q_{\mathrm{n}}^{*}=\min \left(\sqrt{\frac{2 c D_{\mathrm{n}}}{s}}, D_{\mathrm{n}} \Delta t_{e}\right), \\
& Q_{\mathrm{p}}^{*}=\min \left(D_{\mathrm{p}} \sqrt{\frac{2 c}{s D_{\mathrm{n}}}}, D_{\mathrm{p}} \Delta t_{e}\right), \\
& \Delta t_{i}^{*}=\min \left(\sqrt{\frac{2 c}{s D_{\mathrm{n}}}}, \Delta t_{e}\right) .
\end{aligned}
$$

In other words, either the storage cost of the nonperishable good or the expiry time on the perishable will govern the repurchase cycle. The perishability constraint binds when

$$
\sqrt{\frac{2 c}{s D_{\mathrm{n}}}}>\Delta t_{e}
$$

Thus, shopping intervals controlled by expiry time of perishables are more likely with high trip costs, low storage costs, low consumption rates, and short product lifetimes. The minimal costs (we abstract from the price costs here since they do not affect the consumer's decision when only one store is shopped at) in the binding and nonbinding cases, respectively, are

$$
\begin{aligned}
& C_{\mathrm{b}}^{*}=\frac{c}{\Delta t_{e}}+\frac{s D_{\mathrm{n}} \Delta t_{e}}{2}, \\
& C_{\mathrm{nb}}^{*}=\sqrt{2 s D_{\mathrm{n}} c} .
\end{aligned}
$$

\subsection{Optimal policy when both stores are visited}

The optimal shopping pattern in this case is periodic, with period $\Delta t_{\mathrm{n}, \mathrm{d}}$, illustrated in Fig. 1. This represents, for example, purchasing several weeks supply of spaghetti and one week's supply of tomatoes at the discount store, and then restocking the tomatoes several times at the regular store.

The optimal shopping pattern for a consumer is found by solving the following problem:

$$
\begin{aligned}
& \text { Minimize } C \\
& Q_{\mathrm{n}, \mathrm{d}}, Q_{\mathrm{p}, \mathrm{d}}, Q_{\mathrm{p}, \mathrm{r}}, m
\end{aligned}
$$

where minimization is over quantities, and $m$, the number of trips per period to the regular store, subject to the perishability constraints,

$$
\begin{aligned}
& \Delta t_{\mathrm{p}, \mathrm{r}} \leq \Delta t_{e} \\
& \Delta t_{\mathrm{p}, \mathrm{d}} \leq \Delta t_{e}
\end{aligned}
$$

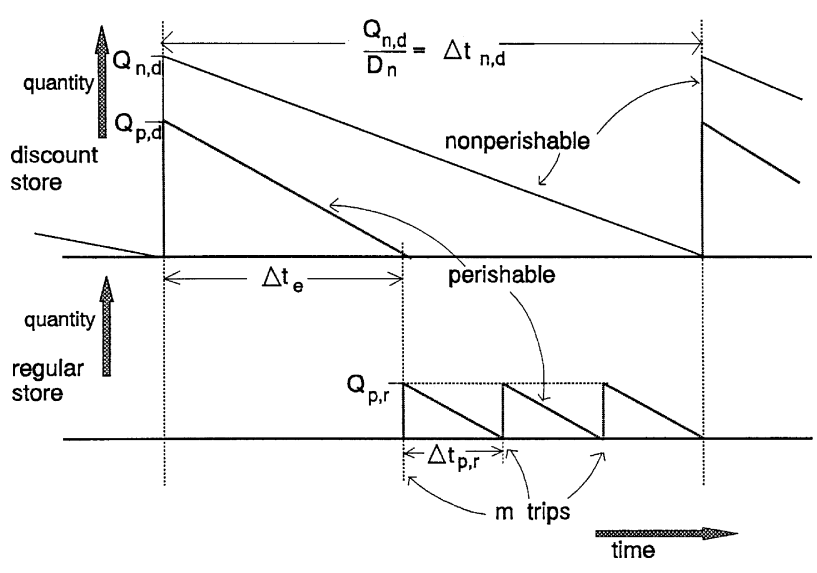

Fig. 1. Example of one period of a typical optimal shopping pattern when both stores are visited. The period is delineated by visits to the discount store, with $m$ visits to the regular store occurring after the perishable purchased at the discount store has been consumed.

The solution for the binding and nonbinding minimum costs (derived in the Appendix) are more complex than in the case of single store shopping, but has the same directional dependence on parameters.

With the six cost functions (for the three shopping patterns, each constrained and unconstrained) in hand, we can determine the pattern of shopping, the trip frequencies to each store, and the quantities of each good purchased on each trip to each store, given price and transportation cost sensitivities, and stockpiling costs for perishables and nonperishables. For any particular distribution of these characteristics over consumers, we can then calculate trade areas and market shares.

These results are used in the next section to study optimal consumer shopping patterns.

\section{Two-dimensional trading areas and market shares}

We next study a numerical example of the consequences of the model for the shopping behavior of spatially heterogeneous customers, and the resulting market areas of the two stores. In the absence of information on other customer-related parameter values, trip costs based on distance can provide a first approximation of market areas, assuming customers are homogeneous on other parameters.

In particular, assume trips costs are proportional to the Euclidean distance between the customer's household and the store. For the regular store:

$$
c_{\mathrm{r}}=\tau \sqrt{\left(x-x_{\mathrm{r}}\right)^{2}+\left(y-y_{\mathrm{r}}\right)^{2}}
$$

where $\tau$ is the sensitivity to travel in dollars per kilometer, the customer is located at $(x, y)$, and the store at $\left(x_{\mathrm{r}}, y_{\mathrm{r}}\right)$. The expression for the discount store trip cost is similar. 
Table 2

Parameter values for the base case calculations

$\begin{array}{ll}\begin{array}{l}\text { Locations } \\ \text { Discount store }\end{array} & \begin{array}{l}(x, y)=(-5,0) \\ (x, y)=(5,0)\end{array} \\ \text { Regular store } & \\ \text { (store separation }=10 \mathrm{~km}) & \\ \text { Prices } & P_{\mathrm{p}, \mathrm{d}}=\$ 40.00 / \mathrm{unit} \\ \quad \text { Perishable, discount store } & P_{\mathrm{p}, \mathrm{r}}=\$ 50.00 \\ \text { Perishable, regular store } & \Delta P_{\mathrm{p}}=\$ 10.00 \\ \text { Perishable difference } & P_{\mathrm{n}, \mathrm{d}}=\$ 40.00 \\ \text { Non-perishable, discount store } & P_{\mathrm{n}, \mathrm{r}}=\$ 50.00 \\ \text { Non-perishable, regular store } & \\ \text { Demand rates } & D_{\mathrm{p}}=1 \mathrm{unit} / \mathrm{week} \\ \text { Perishable } & D_{\mathrm{n}}=1 \\ \text { Non-perishable } & \tau=\$ 4.00 / \mathrm{km} \\ \text { Travel cost } & s=\$ 2.00 / \mathrm{unit} / \text { week } \\ \text { Storage cost } & \Delta t_{\mathrm{e}}=1 \text { week } \\ \text { Expiry time } & \end{array}$

Table 2 shows the base case parameter values, which are systematically varied in subsequent calculations.

The households represented by these parameters would spend $\$ 100.00$ per week if they shopped exclusively at the regular store, and $\$ 80.00$ per week if they shopped exclusively at the discount store. Travel costs can be compared to these savings: a difference in $1 \mathrm{~km}$. to the stores means a savings of $\$ 4.00$. Storage costs of $\$ 2$ per unit per week appear relatively small by comparison, but since they are quadratic in quantity purchased, they can readily become meaningful. For example, if the customer stocks up on 4 weeks supply, the storage cost will be $\$ 16.00$ for that purchase. A lifetime of 1 week seems reasonable for many vegetables and dairy products. The consumption rates are fixed at one unit per week, and are essentially scaling parameters. Alternatively, one could think of the above parameters as representing some average of all perishables and all nonperishables purchased by the household. The point is to illustrate the nature of shopping behavior and trading areas that emerge from modeling perishable and nonperishable stockpiling costs, along with the more conventional price and transportation costs.

The parameter values are used to evaluate the optimal (over quantity) cost functions derived in the last section. The smallest of these functions at each point in the plane determines the shopping pattern at that point. These calculations (which are straightforward, but tedious, and therefore not reproduced here) allow us to describe the shopping behavior in the plane in some detail (see Fig. 2). There is a tiny region immediately around the regular store that is its exclusive market area. At about onequarter of a kilometer away, shopping behavior switches to a two-store pattern with all nonperishables purchased at the discount store, and with 4 fill-in trips for perishables at the regular store. Towards the discount store, the

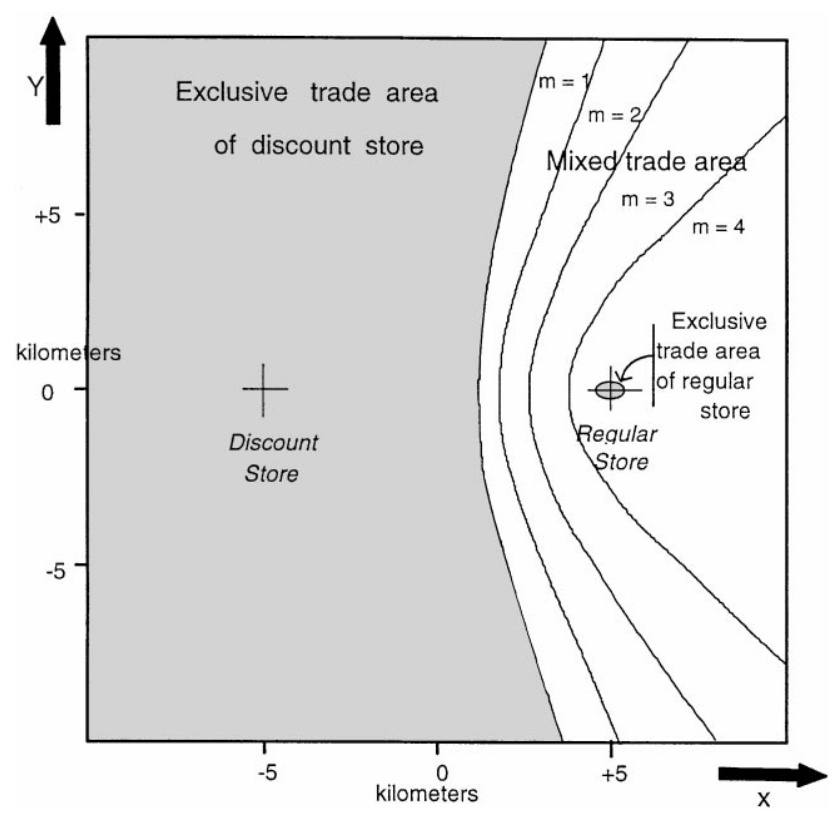

Fig. 2. Representative customer shopping patterns in the trade area when the discount store is $20 \%$ cheaper than the regular store. For this case, the discount store has a large exclusive area and the regular store a very small exclusive area, and about $40 \%$ of customers use a twostore shopping pattern similar to Fig. 1.

behavior goes through progressively fewer fill-in trips, until eventually shopping is done only at the discount store.

From these market areas, market shares can be calculated from a given population density distribution. For illustration, assume that the city is the twenty by twenty kilometer square area that has been plotted, and that the population is uniformly distributed up to the boundaries of the city, and zero outside the boundaries. The regular store's share of nonperishable sales is $0.03 \%$, and the discount store's share is $99.97 \% .^{5}$ The discount store captures $71.86 \%$ of the perishables, and the regular store has a $28.14 \%$ share.

The model has two parameters under the control of management: price and store location. Price, of course, is a much shorter term strategic variable, and it is interesting to see what happens to the market areas as the price difference changes. Reducing the price difference to $10 \%$ gives the trading areas shown in Fig. 3. The regular store now has a large market area exclusively its own. The mixed behavior is confined to a narrow region between the two exclusive areas. The regular stores' nonperishable share has increased from near zero to $36.6 \%$, and it's perishable share from 28 to $40.5 \%$. Changing the price difference between stores from 20 to $10 \%$ affects the share of nonperishables much more than perishables.

\footnotetext{
${ }^{5}$ The detailed calculations are available from the authors.
} 
If we increase the price difference beyond $20 \%$, the regular store no longer has any exclusive shoppers, and will sell no nonperishable goods. Together, these results give a sense of how shopping patterns and shares change with price differences. We next investigate in more detail the impact of price differences, nonperishable storage costs, and perishable lifetimes, on shopping behavior.

Figs. 4 and 5 show the percentage of the customers in the city who engage in each of the three main types of

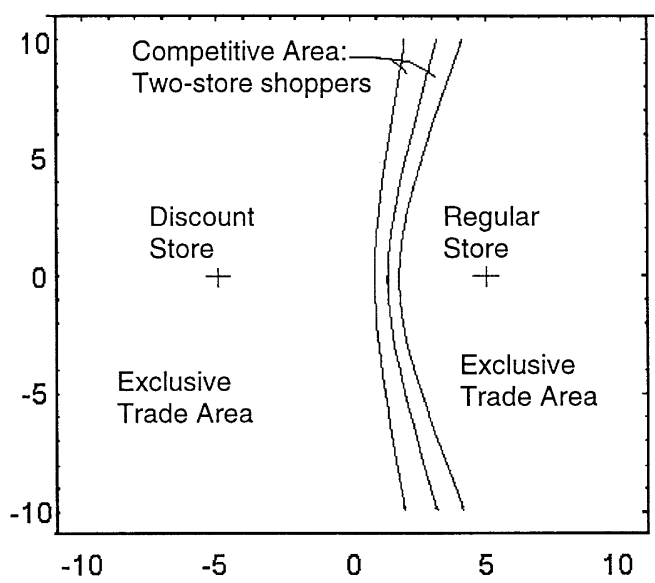

Fig. 3. Shopping patterns in the trade area when the price difference between stores is reduced to $10 \%$ (from $20 \%$ in Fig. 2). About $40 \%$ of the customers shop exclusively at the regular store, and two-store shopping is confined to a narrow strip between to the two stores. shopping behavior, as a function of price difference. Fig. 4 also shows how this function depends on nonperishable stockpiling costs, and Fig. 5 shows the dependency on perishable lifetimes. From both figures, as the price difference increases, the number of discountonly shoppers increases linearly, as some shoppers who previously shopped at both stores now find it optimal to shop only at the discount store. At the same time, a switch from regular-only shoppers to both-store shoppers occurs. This latter switch occurs more rapidly than the former, so that the number of two-store shoppers increases as price differences increase. The increase continues until all regular-only shoppers have switched to two-store shopping. The only effect of further increases in price difference is that two-store shoppers switch to discount-only shopping, so that the number of two-store shoppers gradually declines. We expect to actually observe very little, if any, of this limiting consumer shopping behavior, since it implies that there are no regular-storeonly patrons, and that the regular stores sell no nonperishables, neither of which has face validity.

The number of regular-store-only customers (solid line in Figs. 4 and 5) increases, and the limit of no exclusive customers is reached at a higher price difference, with increasing storage costs (Fig. 4), and with decreasing perishable lifetimes (Fig. 5). The number of two-store shoppers correspondingly increases with increasing storage costs (Fig. 4), until the limit of no regular-store

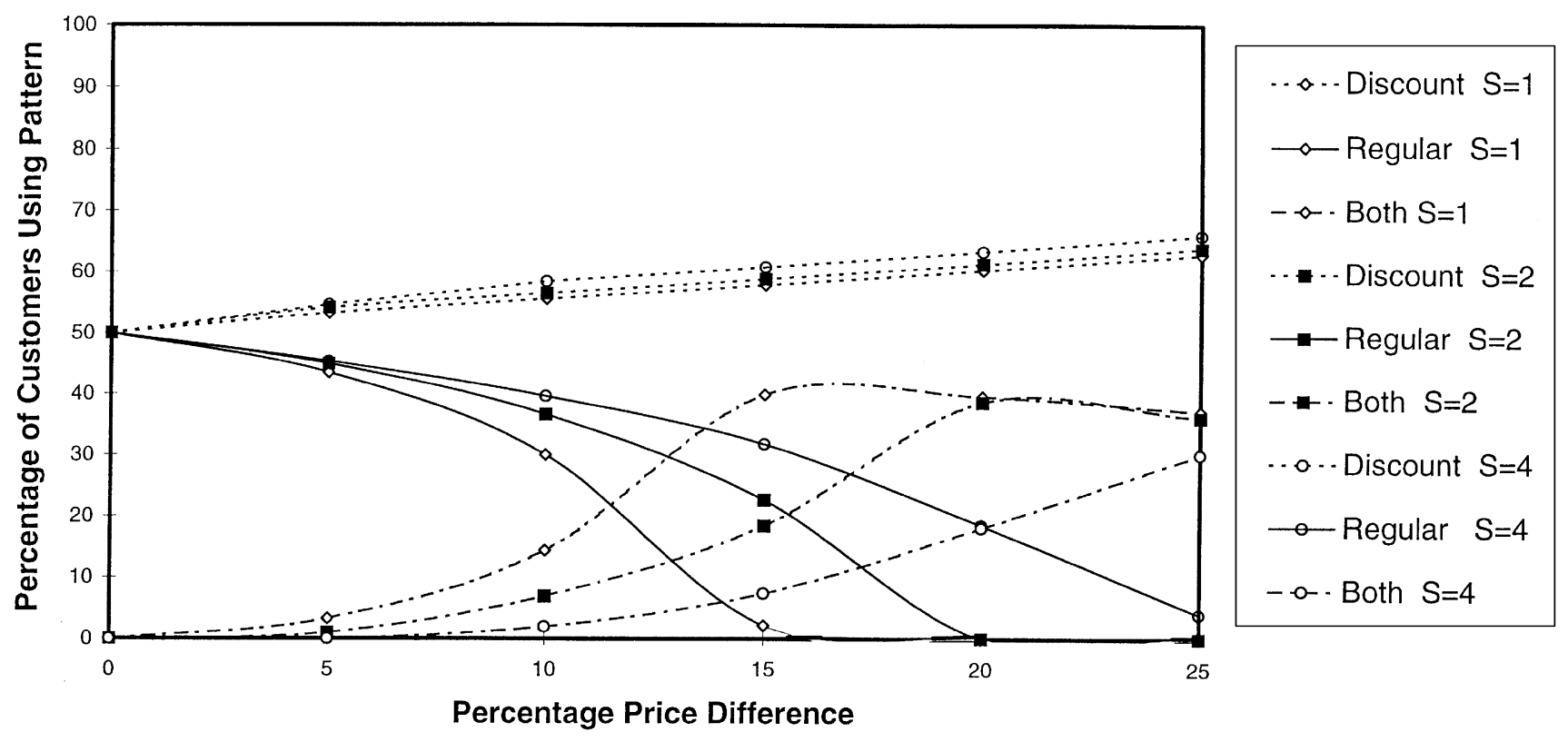

Fig. 4. The effect of price difference and non-perishable storage costs on the proportion of consumers engaging in each of the three types shopping pattern: those shopping exclusively at the discount store (dashed lines), exclusively at the regular store (solid lines) and those engaged in multistore shopping (dot-dash lines). For any price and storage cost, these three total $100 \%$. When there is no difference in price, only single store shopping occurs: the regular store (solid lines) and discount store (dashed lines) split the market. With small price differences, regular store shoppers switch to two-store shopping (dot-dash lines). As the difference increases, the two store pattern rapidly takes over all of the regular store's exclusive customers, while a few of the two-store shoppers (those furthest from the regular store) slowly switch to discount-only shopping. As the nonperishable storage costs increase from $s=1$ (the diamond marker), to $s=4$ (the circle marker), the process of switching from regular-only to two-store patterns is inhibited; these storage costs, however, have little effect on the proportion of discount-only shoppers. 


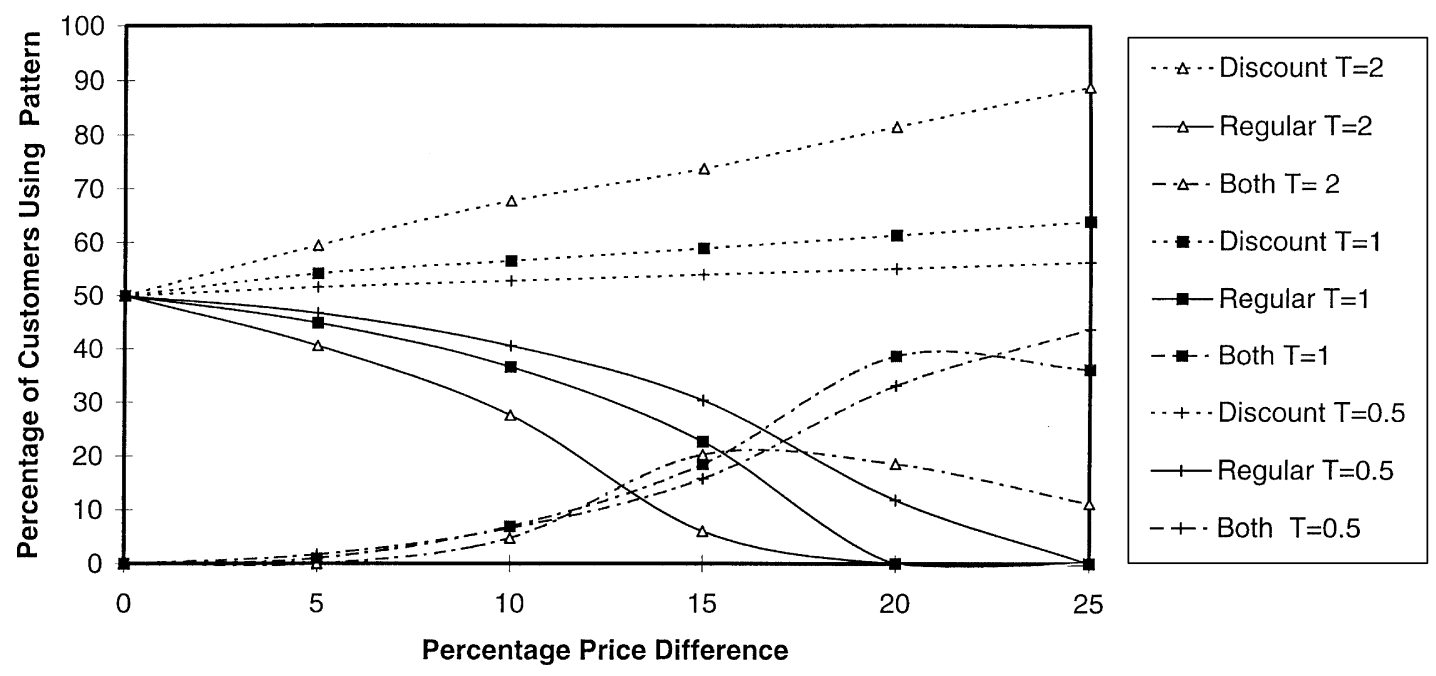

Fig. 5. The effect of price differences and perishable lifetimes on shopping patterns. The three types of lines represent the three types of patterns and sum to $100 \%$, as in Fig. 4. We see the same price effects as in Fig. 4, but, in contrast to the effect of non-perishable storage costs in Fig. 4, the perishable lifetimes have strong effect on the rate at which two-store shoppers (dot-dash) switch to the discount-only (dash) pattern. As long as there are some regular-only shoppers, the number of two-store shoppers stays roughly the same as a function of perishable lifetimes, because customers close to the regular store switch to two-store shopping at about the same rate as two-store shoppers, further from the regular, switch to discount-only shopping.

shoppers is reached, at which point storage costs no longer have an effect. The effect of perishable lifetimes on the two-store shoppers is somewhat different. Since decreasing perishable lifetimes causes discount-only shoppers to switch to two-store shoppers at nearly the same rate as two-store shoppers switch to regular-only, there is very little effect of perishable lifetimes on the number of two-store shoppers, until the limit of no regular-store shopping is reached. We summarize the impact of the three parameters on the three types of shopping behavior, in the cases when all three are possible (and in particular, when there are some regular-only shoppers) in the following three results.

Result 1 (Perceived price differences and shopping behavior). As perceived price differences between stores increase, the major effect is that the proportion of regular store shoppers decreases, and the proportion of two-store shoppers increases. The proportion of exclusive discount shoppers also increases, but at a much lower rate: most of the action involves switching between regular and twostore shopping.

Result 2 (Nonperishable stockpiling costs and shopping behaviour). As storage costs increase, the proportion of regular-only shoppers increases, and two-store shoppers decreases. The effect on proportions of exclusive discount shoppers is negligible.

Result 3 (Perceived perishable lifetimes and shopping behavior). As perceived perishable lifetimes increase, the proportion of discount-only shoppers increase, and regular-only decrease. The proportions of two-store shoppers show small and inconsistent effects.
Figs. 4 and 5 and the above results describe store patronage, but not what is purchased where. To highlight purchases, Figs. 6 and 7 show the discount store's share of perishables and nonperishables (the regular store's patterns are complementary). Fig. 6 shows shares as a function of price advantage for various values of $s$, the storage cost of the nonperishable. Fig. 7 shows the same for various lifetimes of the perishable good. If single store shopping is optimal for all consumers (i.e., no multistore patronage), as occurs at low price differences in the figures above, shares of the two types of goods will be equal. For example, if the discount stores share of spaghetti is $55 \%$, its share of tomatoes will also be $55 \%$. The share difference between goods occurs when it is optimal for some consumers to shop at both stores, as occurs at higher price differences. In this case, the discount store's share of tomatoes might be $75 \%$, but its share of spaghetti could be $95 \%$. The more consumers engage in multistore shopping for the reasons implied by this model, the greater the difference in the perishable and nonperishable market shares of the discount and regular stores. We can summarize the impact of price differences and perishability costs shown in these figures in the following two results.

Result 4 (Market share response to price differences). (i) The nonperishable share exhibits strong increasing returns to scale with price advantage until share approaches $100 \%$. (ii) The share of the perishable good is less sensitive to price advantage than the nonperishable good.

We have a positive second derivative in the response of share to price, until the market is nearly saturated. While 


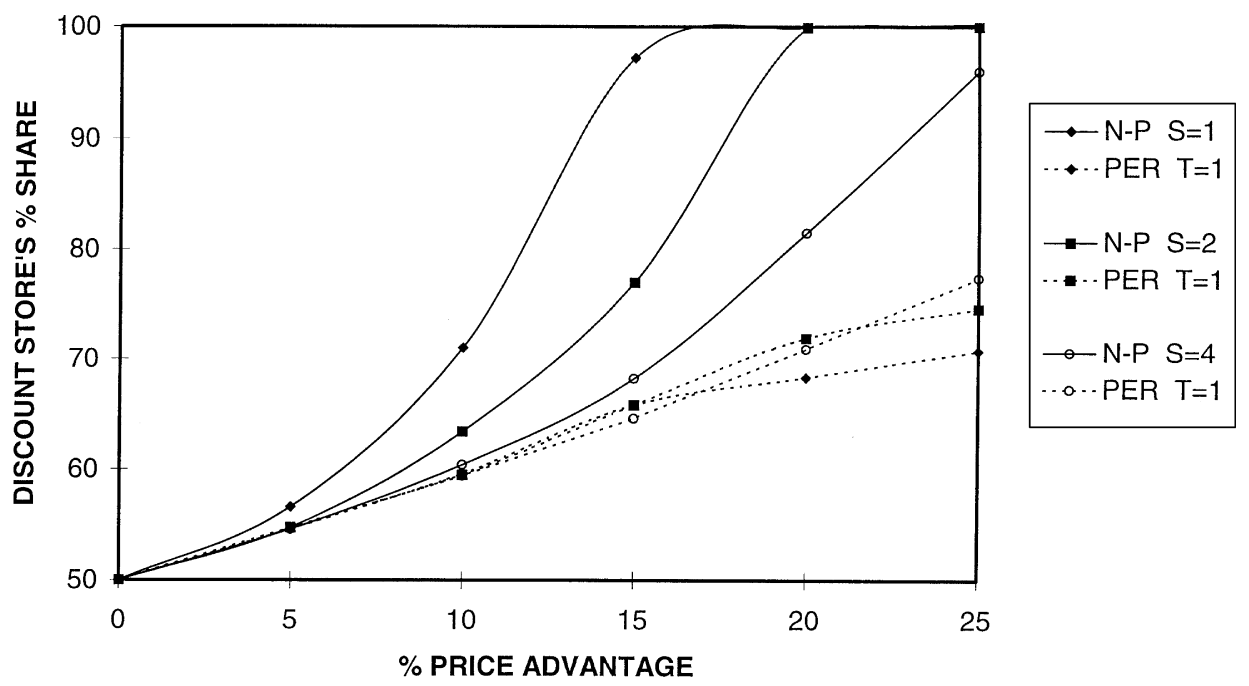

Fig. 6. The discount store's share of both goods as function of price difference and non-perishable storage cost, with perishable lifetime fixed at $T=1$. Non-perishable sales (solid lines) are much more sensitive than perishables (dashed lines) to price advantage (reflecting the shopping patterns shown in Figs. 4 and 5), and this sensitivity increases (circle to square to diamond markers on the solid lines) with decreasing customer storage costs. Perishable sales are not affected by non-perishable storage costs.

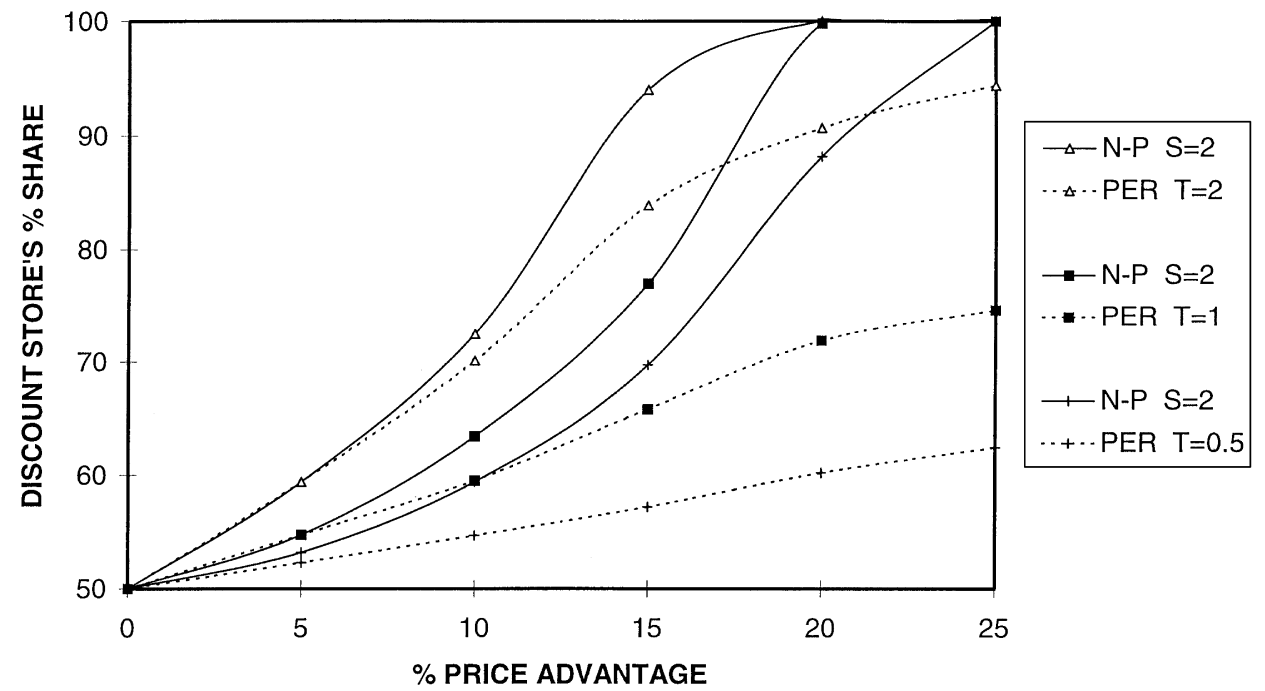

Fig. 7. The discount store's share of both goods as a function of price difference and perishable lifetime, with non-perishable storage costs fixed at $s=2$. The discount store's share of perishables (dashed lines) is very sensitive to perishable lifetime. Interestingly, the non-perishable share is also affected by perishable lifetime, although not as strongly as perishable share.

S-shaped responses to marketing mix variables are not new, the convex portion is generally due to a threshold effect and hence confined to a much more restricted range. Here, the ability to stockpile amplifies the pricedistance trade-off for consumers. Furthermore, without considering the impact of stockpiling on long-term store choice and shopping behavior, incumbents in a market with small price differences would only be aware of the linear portions of the response (the region at less than 5\% in Figs. 6 and 7), and would have no reason to suspect increasing returns. In the face of the entry of a new cost-efficient discount retailer, these incumbents would reasonably project (intuitively or formally) the linear region, and hence would seriously underestimate the impact of the discount retailer's entry. An example where this occurred is the entry of the Real Canadian Superstore (RCS) in western Canadian cities during the last decade. According to private communications with consultants and academics in Vancouver, Edmonton and Winnipeg, Safeway, the dominant and very sophisticated 


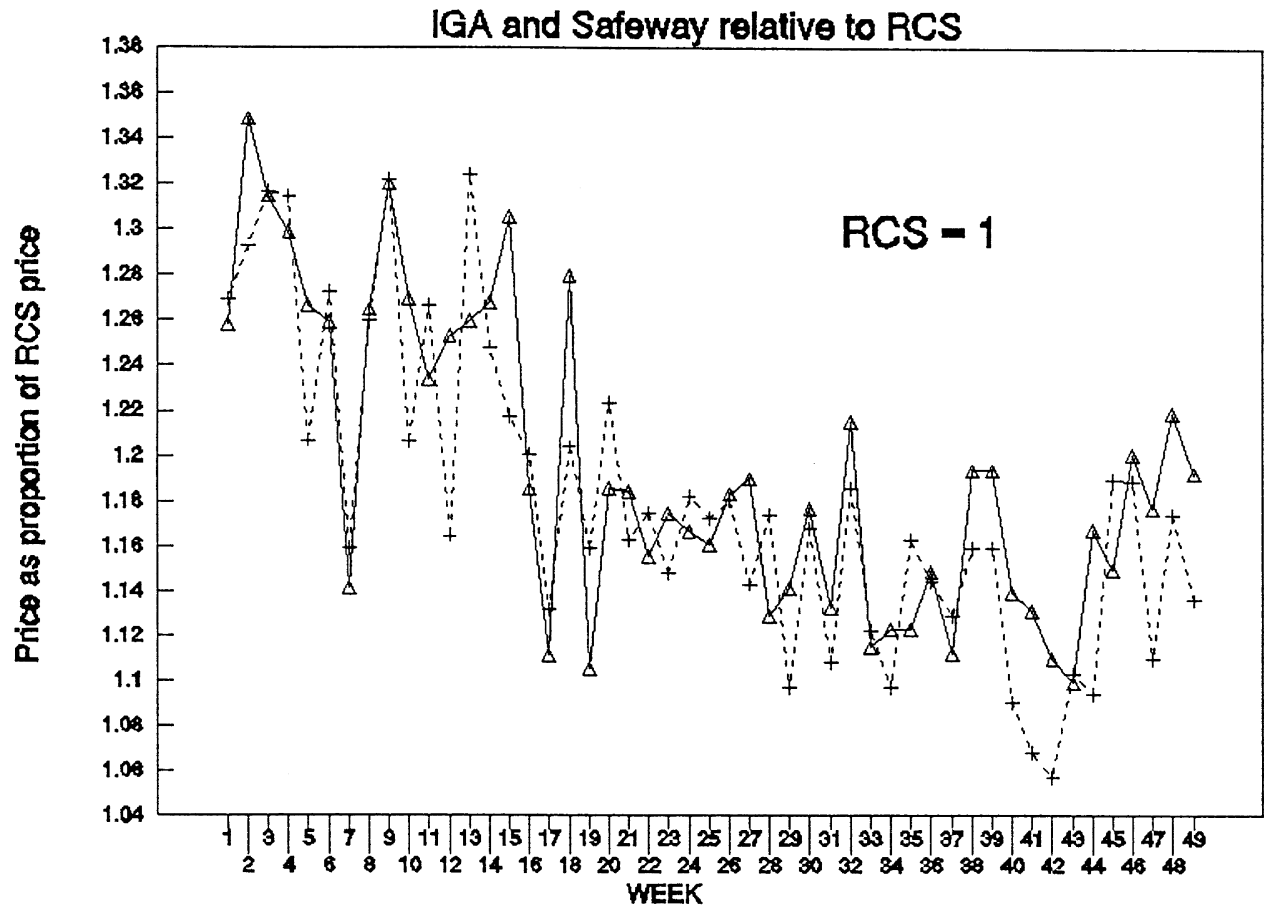

IGA

\section{$\Delta$ Safeway}

Fig. 8. Weekly prices of a (approximately C\$100) food basket, at IGA and Safeway (regular supermarkets), relative to the price at RCS, the discount retailer. (Week $1=$ Jan 6).

incumbent grocery retailer, was "very surprised" by the success of RCS. ${ }^{6}$ The increasing returns effect offers an explanation as to why. (Safeway never regained the lost share, nor matched RCS' prices). Our explanation of this surprise - as unawareness of the nonlinearity arising from the rapid increase in mixed store shoppers who stockpile nonperishables - requires price differences between RCS and the supermarkets that are substantially greater than price differences among supermarkets. Fig. 8 shows that this was indeed the case, with actual price differences very similar to the above scenario. On average, IGA and Safeway prices are within $2 \%$ of each other, while both average $18 \%$ above RCS. Projecting the linear region (i.e., at small price differences) of the response function (Figs. 6 and 7) would lead to a forecast of a much lower share for the new low-priced entrant than was actually achieved.

Result 5 (Share response to stockpiling costs) (i) Consumers' nonperishable storage costs have a large impact on the relative share of the nonperishable bought at

\footnotetext{
${ }^{6}$ For example, in the Vancouver area, market shares in 1996 were split approximately equally between traditional supermarket chains such as Safeway, and the newer discounters such as Real Canadian Superstores, but the regular supermarkets have more than three times as many stores as the discounters.
}

the regular store vs the discount store, but a negligible impact on the relative share of the perishable. (ii) Increasing the lifetime of the perishable has a large impact on relative shares of both the perishable and nonperishable goods.

Result 5, besides noting the expected sensitivities of the goods' shares to their own stockpiling costs, implies asymmetry of cross-effects of stockpiling costs: the stockpiling costs for nonperishable goods have little impact on shopping behaviors for perishables; the deterioration-related stockpiling costs for perishable goods, however, have a substantial effect on shopping behavior for nonperishables. Customer judgment of freshness is therefore critical. Technologies to extend the expiry time of perishable goods (such as new hybrid varieties of produce) to increase in-store shelf life, can help the discount store disproportionately if the expiry time is also extended in the consumer's home. From the regular store's perspective, decreasing the time the consumer is willing to store perishables can provide a defense against the discount store. This may be accomplished by strategies aimed at increasing consumer sensitivity to freshness. ${ }^{7}$

\footnotetext{
${ }^{7} \mathrm{~A}$ related implication is that in a culture where freshness is valued very highly, it may be difficult for large discount formats to operate, even if they only handle non-perishables. See, for example, Marketing News, 1 August 1994, p. 1 for a discussion of Wal-Mart's warehouse club joint venture in Hong Kong. The operation closed down in October 1997.
} 
In terms of the amount of product purchased on each shopping occasion, an interesting result from our theoretical and numerical analyses is that only nonperishables bought at the discount store by two-store shoppers are very sensitive to travel time to the store. While one-store shoppers might be expected to increase the amount purchased as their travel time to the store increases, the perishability constraint puts an upper limit on the amount purchased per trip, and on the distance beyond which the quantity purchased will increase. Numerical analysis suggests that this distance is relatively small; that is, the trip frequency and hence quantities purchased are governed by the lifetime of perishable goods for most single-store consumers. By contrast, mixed-store shoppers, by increasing the number $(m)$ of fill-in trips they make for perishables, can economically increase the amount of nonperishables purchased at the discount store on each shopping trip. This quantity can therefore be traded-off with travel costs for much greater distances (see Fig. 1).

Result 6 (Purchases per trip). In discount stores, (i) the amount of nonperishable purchased will be related to travel costs, and (ii) the amount of perishable purchased will not be related travel costs. In regular stores, neither (i) the amount of nonperishable purchased, nor (ii) the amount of perishable purchased will be related to travel costs.

In the following section, we describe a shopping survey designed to test a subset of the above results.

\section{Empirical results from a grocery shopping survey}

\subsection{Empirical propositions}

An initial motive for this research is to explain planned, long-term multistore shopping by consumers who have good overall knowledge of price differences among grocery stores, and who do not engage in short-term, opportunistic shopping (cherry picking). Our analytical results show that, even when the stores offer identical goods, even if there is no uncertainty either in prices to justify search, or in consumption to justify fill-in trips, and even if there are no promotions to encourage store switching, consumers may find it optimal to engage in planned, long-term, multiple store shopping when stores differ on prices and goods differ on perishability. We then predict how differences in customer characteristics should affect the likelihood of planned multistore shopping - if our model is a reasonable approximation of reality - in the form of results that can be used to challenge the theory. Results 1-3 are summarized in a testable form in the following proposition: ${ }^{8}$

\footnotetext{
${ }^{8}$ In this and the remaining propositions, we use "perceived" parameters, since it is customer perceptions of price, perishability, and storage costs that will drive their shopping behavior.
}

Proposition 1 (Multistore shopping). The tendency to regularly patronize both discount and regular grocery stores increases with (i) greater perceived overall price differences between stores and (ii) lower storage costs; however, (iii) for any combinations of perceived price, perishable lifetimes, and storage costs where some customers shop only at the regular store, the tendency to shop at both stores is not affected by the perceived lifetimes of perishable goods.

We believe that none of these are intuitively obvious, and the first is arguably counter-intuitive if only conventional reasons for patronage of more than one store are considered. Specifically, the overall payoff from two-store shopping due to acquiring deal information, and thus getting better price deals, should decrease as the long-run shopping-basket price differences between stores increases. If the payoff decreases, multistore shopping behavior should decrease, rather than increase as our theory predicts. The second and third predictions have no obvious conventional counterparts.

The third prediction relies on regular stores having exclusive shoppers (and hence, selling nonperishables). This has strong face validity in our survey (see below). However, we can also check this requirement by examining the impact of the three parameters (price difference and the two stockpiling parameters) on the tendency to shop only at the regular store, because if the requirement is satisfied for most combinations of parameters that describe shoppers in our survey (and our theory is correct), we should see an effect of each of these parameters on the tendency to shop only at the regular store.

Proposition 2 (Regular-store-only shopping). The tendency to shop at the regular store only increases with (i) greater perceived overall price differences, (ii) higher storage costs, and (iii) shorter perishable lifetimes.

Our final test is of Result 6 which, for convenience, we repeat as a Proposition 3.

Proposition 3 (Purchases per trip). In discount stores, (i) the amount of nonperishable purchased will be related to travel costs, and (ii) the amount of perishable purchased will not be related travel costs. In regular stores, neither (i) the amount of nonperishable purchased, nor (ii) the amount of perishable purchased will be related to travel costs.

\subsection{Food retailing structure in survey area}

A survey was conducted in Vancouver Canada, where food retailing is dominated by five chains. Safeway and IGA are typical supermarkets, with medium sized outlets mainly in the range of $20000-40000 \mathrm{ft}^{2}$. Safeway is the larger chain, with 49 outlets; IGA has 21 . Save-On-Foods, 
a more recent entry in the market, with only 13 (larger) stores, positions itself as competing directly with Safeway, primarily on price. The Real Canadian Superstore (RCS) has six stores of about $100000 \mathrm{ft}^{2}$ each and positions itself as the price leader. About $40 \%$ of the store is devoted to dry goods, and it carries less than half the number of stock keeping units (sku's) that Safeway does. Costco is a large warehouse club, with one outlet. The price positioning is such that we classify Safeway and IGA as regular stores, and RCS and Costco as discount. Save-On-Foods attempts to maintain the same level of variety as Safeway, but at a lower price, so although it is not as strong a discounter as RCS or Costco, we classify it as a discount store. ${ }^{9}$

\subsection{Method}

Shoppers were intercepted as they left the store and asked to participate in the survey by trained interviewers. Pretests were used to refine the questionnaire; they showed that shoppers were willing to complete the three-to-five minute questionnaire. The final survey was done at three Safeway stores, and one IGA, Superstore, and Save-On-Foods store. Costco would not allow the interviewers to conduct the survey on their property. Surveys were done Friday afternoons, Saturdays and Sundays over two weekends. Four hundred forty one shoppers were approached, and 271 agreed to be interviewed. While all 271 completed the questionnaire, some respondents omitted some questions.

\subsection{Measures and tests for proposition 1 and 2}

\subsubsection{Shopping pattern category}

To test the predictions of Proposition 1 on the determinants of two-store shopping, we first used a classification question to identify the primary shopping pattern for each respondent. On the basis of pretests, four patterns (plus a fifth, "other") were presented, and the respondent asked to select one or more pattern that characterized the way they shopped. These patterns and the number of respondents in each are: ${ }^{10}$

A. I grocery shop almost entirely at one store $(n=120)$.

B. I shop for produce mostly at one store, and do the rest of my grocery shopping mostly at another store $(n=68)$.

C. I shop for groceries at both regular supermarkets (like Safeway) and at discount stores (like RCS and Costco) $(n=57)$.

\footnotetext{
${ }^{9}$ In the consumer survey described below, customer perceptions of price were consistent with this positioning. Moreover, customers shopping at a discount store travel a significantly greater distance than customers shopping at a regular store, as classified by this scheme.

${ }^{10}$ Only four respondents chose more than one pattern.
}

D. Each week I check the advertised specials, and I go to the store with the best prices on what I need $(n=23)$.

E. Other (describe) $(n=3)$.

This distribution of self-reported shopping patterns is consistent with those found by Urbany et al. (1996) in a major midwestern US city. Most notably, only 23 of 271 reported explicit "cherry picking" behavior in their store choice. In terms of our strict definition of the three types of patterns, we find that 114 shopped exclusively at either a discount or regular store, and 44 split their purchases between a discount and regular store. An interesting deviation from our model scenario is the existance of small supermarkets specializing in fresh produce only. Of the 68 respondents who buy produce exclusively in one store (type "B" shoppers), 50 use the specialty produce stores. We do not model such a store, and so do not include these shoppers in our analysis. However, as we discuss in the conclusions, these stores could be playing the role of our modeled regular stores who simply do not have any exclusive shopping area, and hence cannot sell any nonperishables.

After each pattern question, the interviewer asked several questions on exactly which stores were used, and amounts spent on perishables and nonperishables.

To test Proposition 1, we selected shoppers who systematically use both discount and regular stores, so that their characteristics could be compared against those who use only one store. The two groups are defined based on responses to the above pattern questions: ${ }^{11}$

Group 1 (One-store-only shoppers): Shoppers who shop almost entirely at one store (response pattern A above), with either the regular store (Safeway, IGA) or the discount store (RCS, Save-On-Foods, Costco) as the main store $(N=114)$.

Group 2 (Two-store shoppers): Shoppers who regularly split their shopping between stores (response patterns B or C above), with either Safeway or IGA as one store, and either RCS, Save-On-Foods or Costco as the other store $(N=44){ }^{12}$

Similarly, to test Proposition 2, we selected regularonly shoppers for comparison against shoppers systematically using other patterns:

Group 1 (Regular store only shoppers): Shoppers who shop almost entirely at a regular store (response

\footnotetext{
${ }^{11}$ Other shopping patterns, e.g., "D", were not considered in this analysis.

${ }^{12}$ Group 2 shoppers consisted mainly of pattern C respondents (38 of the 44). Most of the pattern B shoppers purchased produce in specialty produce-only stores, rather than supermarkets. While special shopping trips to a higher price store solely for the purchase of perishables is consistent with the pattern predicted by the model, our formulation does not include stores which stock only perishables, and so we make the conservative choice not to include shoppers who use this pattern.
} 
pattern A, with either Safeway or IGA as the main store) $(N=56)$.

Group 2 (Others): Shoppers who shop almost entirely at a discount store (response pattern A with RCS, Save-On, or Costco as the main store), or who split their purchases between regular and discount stores (patterns B or C, with one store being either Safeway or IGA, and the other being either RCS, Save-OnFoods or Costco $)(N=82)$.

\subsubsection{Perceived price differences}

Respondents were asked to estimate percentage savings at the less expensive store on perishables and nonperishables separately. Almost two-thirds reported the same savings for perishables and nonperishables, and only 16 of the 158 reported savings differing by more than $10 \%$. Since most respondents see little differences, and since the proposition is based on store-level savings, the variable SAVE is the mean of the perishable and nonperishable perceived savings.

\subsubsection{Perceived perishability}

We constructed a measure of "perceived perishability" by asking respondents to estimate the number of days that four different products (tomatoes, bananas, milk, and bread) could be stored in their home before they had to be thrown out. The variable LIFE, the mean of these four estimates, captures the individual shopper's sensitivity to perishability.

\subsubsection{Storage cost}

The consumer's storage cost (STORAGE) is related to storage space, which we measure indirectly by asking how many freezers each household has. We assume that as the number of freezers increases, so will the overall food storage space. While it would be preferable to have a more direct measure of storage space, or of the sensitivity to storage costs, this question is easy to answer, and hence relatively noise-free.

\subsubsection{Income}

Respondents identified which of six categories their household income fell into. The variable INC is taken as the midpoint of these categories. We do not have a specific hypothesis for the effect of income, but since it typically affects shopping behavior (e.g., Hoch et al. 1995; Urbany et al. 1996), we chose to control for it.

\subsubsection{Model}

The binary logit of the probability of single store shopping (as opposed to two-store shopping) for Proposition 1, and of regular-only shopping (as opposed to discount-store shopping) for Proposition 2, was modeled as a linear function of the four independent variables:

$$
\log \left[\frac{P\left(y_{i}=1\right)}{1-P\left(y_{i}=1\right)}\right]=B_{0}+\sum B_{i} X_{i}
$$

where $Y_{i}=1$ if the respondent belongs to group 1, and zero otherwise. Parameters were estimated by maximum likelihood, using SAS LOGISTIC.

\subsection{Results for proposition 1}

The likelihood ratio tests show that inclusion of the four variables improves the fit over the intercept-only model significantly $\left(\chi^{2}=28.8, p<0.0001\right.$; see Table 3$)$.

STORAGE and SAVE are significant and have the predicted sign. LIFE is not significant, again as predicted. In particular, the greater the perceived price difference, the more likely is the consumer to engage in multiplestore shopping. This result also holds if only regular store shoppers are compared to mixed store shoppers $(p<0.01)$, and directionally if only discount store shoppers are compared to mixed store shoppers $(p>0.1)$.

The storage cost variable, STORAGE, is also significant. The greater the storage space, the more likely that the consumer shops at both discount and regular stores. Again, the result holds $(p<0.05)$ if the regular and discount store shoppers are compared separately with mixed store shoppers. The perishability variable, LIFE, is not significant, as would be expected if most shoppers' characteristics satisfy the non-limiting requirements described previously.

All results are consistent with Proposition 1, providing strong support.

\subsection{Results for proposition 2}

The likelihood ratio tests show that inclusion of the four variables improves the fit over the intercept-only model significantly $\left(\chi^{2}=26.9, p<0.0001\right.$; see Table 4$)$.

Table 3

Logistic regression estimation of predictors for Propositon 1

\begin{tabular}{lll}
\hline Variable & Predicted sign & $\begin{array}{l}\text { Estimated parameter } \\
(p \text {-value of Wald chi-square })\end{array}$ \\
\hline Intercept & & 4.37 \\
Storage & $(0.0001)$ \\
& - & -0.96 \\
Save & - & $(0.006)$ \\
& & -6.56 \\
Life & Nil & $(0.018)$ \\
& & 0.061 \\
Income & & $(0.46)$ \\
& & -0.00002 \\
Log likelihood & & $(0.04)$ \\
Likelihood ratio & & -69.5 \\
\hline
\end{tabular}


Table 4

Logistic regression estimation of predictors for Propositon 2

\begin{tabular}{lll}
\hline Variable & Predicted sign & $\begin{array}{l}\text { Estimated parameter } \\
(p \text {-value of Wald chi-square })\end{array}$ \\
\hline Intercept & 2.92 \\
Storage & $(0.0004)$ \\
& - & -0.92 \\
Save & - & $-6.011)$ \\
& -6.8 \\
Life & - & $(0.009)$ \\
& & -0.16 \\
Income & & $-0.050)$ \\
& & $(0.33)$ \\
Log likelihood & & -93.2 \\
Likelihood ratio & $26.9, p<0.0001$ \\
\hline
\end{tabular}

All three (nondemographic) variables are significant and have the predicted sign. Proposition 2 is strongly supported, and further evidence is provided that parameter combinations are such that most customers are in the nonlimiting region.

\subsection{Measures and test for proposition 3}

\subsubsection{Transportation cost}

Travel time is taken as the main component of transportation cost. The variable TRAVEL TIME is the response to the question "how long did it take you to get to this store?"

\subsubsection{Actual purchases}

At the end of each interview the respondent was asked for their cash register receipt. 138 receipts were collected, and 133 respondents refused. ${ }^{13}$ For those respondents who did provide receipts, the total value of perishables purchased and the total non-perishable purchases provide the variables ACTPBILL and ACTNPBILL respectively.

\subsubsection{Estimated purchases}

Because some respondents kept their receipts, and because actual shopping behavior is driven by the perceptions of what is being purchased rather than the actual purchases, all 271 respondents also estimated their total bill (ESTBILL) and the percentage which was perishables. This was used to calculate the related variables, ESTPBILL and ESTNPBILL.

\subsubsection{Income}

The previously described income measure was included as a control variable.

\footnotetext{
${ }^{13}$ The two groups did not differ significantly $(p<0.05)$ on their estimated bill, nor on three of the four independent variables. Those who gave us receipts had slightly fewer freezers per household than those who did not (1.53 vs 1.32 ).
}

\subsection{Test procedure and results}

Regressions for each of the four purchase measures were run separately for the discount stores (RCS and Save-On) and the regular stores (IGA and Safeway), for a total of eight models. Results are reported in Table 5. Overall $F$-tests achieved significance $(p<0.05)$ only for nonperishables purchased at discount stores, and only travel time is a significant predictor $(p<0.005)$ of purchase amounts for these two regressions. These results hold whether the actual or estimated bills are used as the dependent variable. Proposition 3 is supported.

\section{Conclusions}

We have shown that consideration of consumer stockpiling, and the fact that some goods are perishable and others not, is important in determining consumers' planned shopping behavior between stores differentiated on location and price, and in the market share of competing retailers.

While the retailing and promotions literature recognizes that loyalty to one store may be low, the possibility of a multistore shopping strategy resulting from the combination of long-run average price differences between stores and the fact that some groceries are perishable and others are not, has not been considered. Our results show that multistore shopping behavior can arise endogenously for (some) consumers. We make a series of predictions of how customer perceptions of price, and consumer sensitivity to storage costs and perishability, should affect planned multistore shopping, and find strong support for these predictions. One particular empirically substantiated result that is difficult to explain using only cherry-picking models of multistore patronage, is that multistore shopping increases with perceived increases in shopping basket savings at the discount store.

An unexpected and interesting result, the non-linear market share response function, suggests a reason why incumbents do not expect entering "power" retailers to be as dramatically successful as they sometimes are. When price differences are small, consumers behave as if they are simply trading off price and distance. Extrapolating this behavior to larger price differences, however, underestimates the share of a new, low-price entrant, because consumer stockpiling behavior becomes more important. The effect also highlights the competitive importance of achieving major cost efficiencies, such as by supply-chain management, that can be passed on to customers as lower prices.

The model also suggests a unique role for perishable goods as a defense against price competition, and as an impediment to the expansion of some western-style food retail formats to developing countries. Consumer willingness and ability to store perishables can have 
Table 5

Regression results for purchase amount (\$) by store (regular/discount) and product (perishable/non-perishable) type

\begin{tabular}{|c|c|c|c|c|}
\hline & Discount & Store & Purchases & \\
\hline Variable & $\begin{array}{l}\text { Actual } \\
\text { perishable } \\
n=41\end{array}$ & $\begin{array}{l}\text { Actual } \\
\text { nonperishable } \\
n=41\end{array}$ & $\begin{array}{l}\text { Estimated } \\
\text { perishable } \\
n=89\end{array}$ & $\begin{array}{l}\text { Estimated } \\
\text { nonperishable } \\
n=89\end{array}$ \\
\hline Intercept & 9.6 & 11.7 & 24.4 & -13.5 \\
\hline Travel time & 0.12 & $1.39^{\mathrm{b}}$ & 0.007 & $1.58^{\mathrm{b}}$ \\
\hline Income (000's) & 0.02 & 0.2 & 0.14 & 0.38 \\
\hline \multirow[t]{2}{*}{$F$-ratio } & 0.33 & $4.90^{\mathrm{a}}$ & 0.22 & $9.79^{a}$ \\
\hline & Regular & Store & Purchases & \\
\hline Variable & $\begin{array}{l}\text { Discount } \\
\text { Actual } \\
\text { perishable } \\
n=83\end{array}$ & $\begin{array}{l}\text { Store } \\
\text { Actual } \\
\text { nonperishable } \\
n=83\end{array}$ & $\begin{array}{l}\text { Purchases } \\
\text { Estimated } \\
\text { perishable } \\
n=156\end{array}$ & $\begin{array}{l}\text { Estimated } \\
\text { nonperishable } \\
n=156\end{array}$ \\
\hline Intercept & $8.32^{\mathrm{b}}$ & 14.1 & $8.97^{\mathrm{a}}$ & 8.91 \\
\hline Travel time & -0.06 & 0.02 & -0.17 & 0.30 \\
\hline Income (000's) & -0.01 & 0.2 & 0.01 & $0.17^{\mathrm{a}}$ \\
\hline$F$-ratio & 0.09 & 1.28 & 2.82 & 2.56 \\
\hline
\end{tabular}

${ }^{\mathrm{a}} p<0.05$.

${ }^{\mathrm{b}} p<0.005$.

a major impact on the share of both perishables and nonperishables bought in different store formats. ${ }^{14}$

\subsection{Limitations and future research}

The analysis could, in principle, be extended to include many competing stores, or more realistically, competing chains, in arbitrary configurations. A simple extension that we can qualitatively analyze immediately is a supermarket chain of several stores, charging "regular" prices, surrounding a single discount outlet such as a warehouse club. The shopping pattern would appear as superpositions of Fig. 2 rotated about the discount store. For that case, the chain would have much greater share of perishables than in the single store case; however, the nonperishable share, already relatively small for large price differences, would remain so. The supermarket would have the largest share of perishables, and the discount store the largest share of nonperishables. Introducing a supermarket chain accentuates the consequences of differences in perishability, and the importance of perishable goods as defense against the discount outlet.

Consistent with the market situation in Vancouver, it appears that higher price formats have higher spatial density. Is it possible that this is an equilibrium outcome

\footnotetext{
${ }^{14}$ Goldman et al. (1996) have noted that supermarkets are unable to compete effectively with traditional wet markets in fresh foods in many Asian countries.
}

of a scenario where chains make spatial density and price decisions, given that consumers trade off the three costs (price, travel, and storage) considered in this paper? This is an interesting question for competitive marketing strategy. A second competitive strategy question concerns the theoretical implications for equilibrium prices and locations given differences in perishability. From the large literature on spatial competition (e.g., Hotelling, 1929; de Palma et al., 1985; Vandenbosch and Weinberg, 1995), it is known that increased separation on spatial dimensions (either geographic space, or product attribute space) decreases price competition by increasing the strength of the spatial monopoly. In our model, many consumers travel further for nonperishables than perishables, which suggests that price competition should be fiercer for nonperishables. However, if each store carries both goods, interactions may affect this conclusion. As alluded to throughout the paper, the strategic uses of perishable goods is an interesting and relatively unexplored topic.

One of the unexpected observations from the survey was the exclusive use of perishables-only specialty stores by some consumers for all of their perishables. This situation is implicit in our model and related to the differential competitive intensity argument: if the regular store's exclusive region shrinks sufficiently, it is only able to sell perishables. Rational management response would be to only carry perishables. From a more strategic perspective, the growth of discounters with large trading areas provides a strategic opportunity for perishables 
specialists with smaller trading areas. If the traditional supermarkets do not react rapidly, they might be squeezed on nonperishables by the discounters, and on perishables by the specialists.

Consumer sensitivities might be susceptible to manipulation; in fact, one of Safeway's responses to the successful entry of the Real Canadian Superstore was to emphasize convenience of location in their advertising, presumably to increase the consumer's sensitivity to travel costs (i.e., $\tau$ ). From a broader perspective, the range and dynamism of potential competitive responses available may preclude static equilibria (see, for example, Krider and Weinberg, 1997).

While store chains and differential competitive intensity across goods are the most immediately interesting avenues for continuing work, a wide range of firm and customer decision models could be enriched by incorporating perishability. These issues remain for future research.

\section{Acknowledgements}

We wish to thank Tiffany Murray for her valuable assistance in conducting survey data research. Willem Burgers, Gerry Gorn, Jayashree Mahajan, Seshan Ramaswami, and Priya Raghubir provided insightful comments on earlier versions of this paper.

\section{Appendix. Derivation of the two-store cost function}

As indicated in Fig. 1, we have shown (in an appendix available from the authors), under general conditions, that (1) the perishability constraint is always binding on $Q_{\mathrm{p}, \mathrm{d}}$, so it is unnecessary to minimize over that quantity; and (2) the same amount of perishable, $Q_{\mathrm{p}, \mathrm{r}}$, is purchased on each trip to the regular store, so it can be expressed in terms of $Q_{\mathrm{n}, \mathrm{d}}$ :

$$
\begin{aligned}
& m Q_{\mathrm{p}, \mathrm{r}}=\left(\Delta t_{\mathrm{n}, \mathrm{d}}-\Delta t_{e}\right) D_{\mathrm{p}}, \\
& Q_{\mathrm{p}, \mathrm{r}}=\left(\frac{Q_{\mathrm{n}, \mathrm{d}}}{D_{\mathrm{n}}}-\Delta t_{e}\right) D_{\mathrm{p}} / m .
\end{aligned}
$$

Consequently, the minimization need only be done over $Q_{\mathrm{n}, \mathrm{d}}$ and $m$. The cost function is

$$
\begin{aligned}
C= & \frac{D_{\mathrm{n}}}{Q_{\mathrm{n}, \mathrm{d}}}\left(c_{\mathrm{d}}+m c_{\mathrm{r}}+\frac{s Q_{\mathrm{n}, \mathrm{d}}^{2}}{2 D_{\mathrm{n}}}+Q_{\mathrm{n}, \mathrm{d}} P_{n, \mathrm{~d}}\right. \\
& \left.+Q_{\mathrm{p}, \mathrm{d}} P_{\mathrm{p}, \mathrm{d}}+m Q_{\mathrm{p}, \mathrm{r}} P_{\mathrm{p}, \mathrm{r}}\right)
\end{aligned}
$$

Substituting for $Q_{\mathrm{p}, \mathrm{d}}$ and $Q_{\mathrm{p}, \mathrm{r}}$ from above, and letting $P_{\mathrm{p}, \mathrm{d}}-P_{\mathrm{p}, \mathrm{r}}=-\Delta P_{\mathrm{p}}$,

$$
\begin{aligned}
C= & \frac{D_{\mathrm{n}}}{Q_{\mathrm{n}, \mathrm{d}}}\left(c_{\mathrm{d}}+m c_{\mathrm{r}}+\frac{s Q_{\mathrm{n}, \mathrm{d}}^{2}}{2 D_{\mathrm{n}}}+Q_{\mathrm{n}, \mathrm{d}} P_{\mathrm{n}, \mathrm{d}}-D_{\mathrm{p}} \Delta t_{e} \Delta P_{\mathrm{p}}\right. \\
& \left.+\frac{D_{\mathrm{p}} P_{\mathrm{p}, \mathrm{r}} Q_{\mathrm{n}, \mathrm{d}}}{D_{\mathrm{n}}}\right)
\end{aligned}
$$

The effect of the binding perishability constraint (Eq. (8) in the text) on $Q_{\mathrm{p}, \mathrm{d}}$ has already been incorporated into Eq. (1), but constraint (Eq. (7) in the text) on the trip timing to the regular store for perishables is not necessarily binding on $Q_{\mathrm{p}, \mathrm{r}}$. Since $Q_{\mathrm{p}, \mathrm{r}}$ has been eliminated from the cost function, the constraint is rewritten as a minimum on the number of trips that must be taken to the regular store in the period:

$$
m \geq \frac{\Delta t_{\mathrm{n}, \mathrm{d}}-\Delta t_{e}}{\Delta t_{\mathrm{e}}}
$$

or, in terms of $Q_{\mathrm{n}, \mathrm{d}}$ :

$$
m+1-\frac{Q_{\mathrm{n}, \mathrm{d}}}{\Delta t_{e} D_{\mathrm{n}}} \geq 0 .
$$

The number of trips, $m$, must be an integer. Therefore we will first minimize the cost over $Q_{\mathrm{n}, \mathrm{d}}$ conditional on $m$ and subject to constraint (A.5). In the following, the subscripts will be dropped from $Q_{\mathrm{n}, \mathrm{d}}$, as that is the only quantity being dealt with in the optimization.

The cost function (A.3) is convex in Q and the constraint (A.5) is linear. Therefore the Kuhn-Tucker first-order conditions are sufficient for minimization with respect to $Q$. The Lagrangian is

$$
\begin{aligned}
L= & C-\mu\left(m+1-\frac{Q}{\Delta t_{e} D_{\mathrm{n}}}\right) \\
= & \frac{D_{\mathrm{n}}}{Q}\left(c_{\mathrm{d}}+m c_{\mathrm{r}}+\frac{s Q^{2}}{2 D_{\mathrm{n}}}+Q P_{\mathrm{n}, \mathrm{d}}-D_{\mathrm{p}} \Delta t_{e} \Delta P_{\mathrm{p}}\right. \\
& \left.+\frac{D_{\mathrm{p}} P_{\mathrm{p}, \mathrm{r}} Q}{D_{\mathrm{n}}}\right)-\mu\left(m+1-\frac{Q}{\Delta t_{e} D_{\mathrm{n}}}\right) .
\end{aligned}
$$

The first order conditions are

$$
\frac{\partial L}{\partial Q}=\frac{\partial C}{\partial Q}+\frac{\mu}{\Delta t_{e} D_{\mathrm{n}}}=0
$$

and the constraint (A.5). If the constraint is binding, Eq. (A.5) gives

$$
Q_{\mathrm{b}, \mathrm{m}}^{*}=D_{\mathrm{n}} \Delta t_{e}(m+1)
$$

where the subscripts on $Q$ indicate "binding" and dependence on the trip parameter " $m$ ". The minimal (binding) cost is

$$
\begin{aligned}
C_{\mathrm{b}, \mathrm{m}}^{*}= & D_{\mathrm{n}} P_{\mathrm{n}, \mathrm{d}}+D_{\mathrm{p}} P_{\mathrm{p}, \mathrm{r}}+\frac{c_{\mathrm{d}}+m c_{\mathrm{r}}}{\Delta t_{e}(1+m)}-\frac{\Delta P_{\mathrm{p}} D_{\mathrm{p}}}{1+m} \\
& +\frac{s \Delta t_{e} D_{\mathrm{n}}(1+m)}{2}
\end{aligned}
$$


When the constraint is not binding, $\mu=0$, and the first-order condition becomes

$$
Q_{\mathrm{nb}, m}^{*}=\sqrt{\frac{2 D_{\mathrm{n}}}{S}\left(c_{\mathrm{d}}+m c_{\mathrm{r}}-\Delta P_{\mathrm{p}} \Delta t_{e} D_{\mathrm{p}}\right)}
$$

The (not binding) cost is

$$
\begin{aligned}
C_{\mathrm{n}, m}^{*}= & D_{\mathrm{n}} P_{\mathrm{n}, \mathrm{d}}+D_{\mathrm{p}} P_{\mathrm{p}, \mathrm{r}} \\
& +\sqrt{2 D_{\mathrm{n}} s\left(c_{\mathrm{d}}+m c_{\mathrm{r}}-\Delta P_{\mathrm{p}} \Delta t_{e} D_{\mathrm{p}}\right)} .
\end{aligned}
$$

Finally, the constraint binds when $\mu$ is positive. Following the usual Kuhn-Tucker analysis, the first-order conditions imply that

$$
\frac{\partial C}{\partial Q} \Delta t_{e} D_{\mathrm{n}} \leq 0
$$

Differentiating and substituting for the binding value of $Q$ in Eq. (A.8) gives the required relation between the parameters in order for the constraint to bind:

$$
c_{\mathrm{d}}+m c_{\mathrm{r}} \geq \frac{\Delta t_{e}^{2} D_{\mathrm{n}}(1+m)^{2} s}{2}+\Delta P_{\mathrm{p}} \Delta t_{e} D_{\mathrm{p}}
$$

Although more complex than in the case of single store shopping shown in the text, this has the same directional dependence on parameters. Specifically, large travel costs are more likely to lead to the perishability constraint to binding, and determining the shopping period. Note that this is conditioned on $m$, the number of fill-in trips. To determine the precise number of fill in trips for any given set of parameters, both the optimal (over $Q$ ) binding and nonbinding costs for all values of $m$ will have to be compared. What typically happens as travel costs increase is that the optimal quantity purchased increases continuously in the nonbinding fashion, then binds, so that the shopping pattern is locked in for further increases. At some point, however, with additional travel cost increases, it becomes optimal to make another trip so that the pattern shifts to $m+1$ fill-in trips, again in nonbinding mode, and the purchase quantity again increases smoothly, until it again locks in the $m+1$ binding case.

\section{References}

Arnold, S.J., Oum, T.H., Tigert, D.J., 1983. Determinant attributes in retail patronage: seasonal, temporal, regional, and international comparisons. Journal of Marketing Research 20, 149-157.

Atkins, D.R., 1993. Joint replenishment of multiproduct inventories. Unpublished Working Paper, Faculty of Commerce, University of British Columbia.

Bacon, R., 1984. Consumer Spatial Behavior. Oxford University Press, New York.

Baumol, W.J., Ide, E.A., 1957. Variety in retailing. Management Science 3, 93-102.

Blattberg, R.C., Eppen, G.D., Lieberman, J., 1981. A theoretical and empirical evaluation of price deals for consumer nondurables. Journal of Marketing 45, 116-129.
Blattberg, R.C., Neslin, S.A., 1993. Sales promotion models. In: Eliashberg, J., Lilien, G.L. (Eds.), Handbooks in Operations Research and Management Science, vol. 5, Marketing. North-Holland, Amsterdam.

Bucklin, R.E., Lattin, J.M., 1992. A model of product category competition among grocery retailers. Journal of Retailing 68 (3), 271-293.

dePalma, A., Ginsburgh, V., Papageorgiou, Y.Y., Thisse, J.-F., 1985. The principle of minimum differentiation holds under sufficient heterogeneity. Econometrica, 53 (4), 767-781.

Dickson, P.R., Sawyer, A.G., 1990. The price knowledge and search of supermarket shoppers. Journal of Marketing 54, 42-53.

Ghosh, A., McLafferty, S., 1984. A model of consumer propensity for multipurpose shopping. Geographical Analysis 16, 244-49.

Goldman, A., Krider, R., Ramaswami, S., 1996. Supermarket shopping adoption and the modernization of food retailing: theory, method, and application. Department of Marketing Working Paper Series, MKTG 96.073, Hong Kong University of Science and Technology.

Hoch, S.J., Kim, B.-D., Montgomery, A.L., Rossi, P.E., 1995. Determinants of store-level price elasticity. Journal of Marketing Research $32,17-29$.

Hotelling, H., 1929. Stability in competition. Economic Journal 39, 41-57.

Hortman, S.M., Allaway, A.W., Mason, J.B., Rasp, J., 1990. Multisegment analysis of supermarket patronage. Journal of Business Research 21, 209-223.

Ingene, C., Ghosh, A., 1990. Consumer and producer behavior in a multipurpose shopping environment. Geographical analysis, 22 (1), 70-93.

Kahn, B.E., Schmittlein, D.C., 1992. The relationship between purchases made on promotion and shopping trip behavior. Journal of Retailing, 68(3), 204-315.

Krider, R.E., 1993. Nonlinear responses in marketing. Unpublished Doctoral Dissertation, University of British Columbia.

Krider, R.E., Weinberg, C.B., 1997. Spatial competition and bounded rationality: retailing at the edge of chaos. Geographical Analysis 29 (1), 16-34.

Krishna, A., 1994. The impact of dealing patterns on purchase behavior. Marketing Science 13 (4), 351-373.

Kumar, V., Leone, R.L., 1988. Measuring the effect of retail store promotions on brand and store substitution. Journal of Marketing Research 25, 178-185.

Lal, R., Rao, R., 1997. Supermarket competiton: the case of every day low pricing. Marketing Science 16 (1), 60-80.

Lentnek, B., Harwitz, M., Narula, S., 1981. Spatial choice in consumer behavior: toward a contextual theory of demand. Economic Geography, 57, 362-72.

Louviere, J., Finn, A., Timmermans, H., 1995. Retailing research. Working Paper. University of Alberta.

McLafferty, S., Ghosh, A., 1986. Multipurpose shopping and the location of retail firms. Geographical Analysis 18, 215-226.

Messinger, P.R., Narasimhan, C., 1997. A model of retail formats based on consumers' economizing on shopping time. Marketing Science 16 (1), 1-23.

Meyer, R.J., Assuncao, J., 1990. The optimality of consumer stockpiling strategies. Marketing Science 9 (1), 18-41.

Muckstadt, J.A., Roundy, R.O., 1993. Analysis of multistage production systems. In: Graves, S.C., Rinnooy Kan, A.H.G., Zipkin, P.H. (Eds.), Logistics of Production and Inventory. North-Holland, Amsterdam.

Mulhern, F.J., Leone, R.P., 1990. Retail promotional advertising - do the number of deal items and size of deal discounts affect store performance? Journal of Business Research 21 (3), 179-194.

Mulhern, F.J., Padgett, D.T., 1995. The relationship between retail price promotions and regular price purchases. Journal of Marketing 59(4), 83-90. 
Nahmias, S., 1982. Perishable inventory theory: a review. Operations Research 30(4), 680-708.

Raju, J.S., 1992. The effect of price promotions on variability in product category sales. Marketing Science 11 (3), 207-220.

Uncles, M.D., Ehrenberg, A.S.C., 1990. The buying of packaged goods at US retail chains. Journal of Retailing 66 (3), 278-296.

Urbany, J.E., Dickson, P.R., Kalapurakal, R., 1996. Price search in the retail grocery market. Journal of Marketing 60, 91-104.
Vandenbosch, M.B., Weinberg, C.B., 1995. Product and price competition in a two-dimensional vertical differentiation model. Marketing Science 14 (2), 224-249.

Walters, R.G., 1991. Assessing the impact of retail price promotions on product substitution, complementary purchase, and interstore sales displacement. Journal of Marketing 55, 17-28. 